\title{
How Retailers Support Consumers during the Pandemic: Kaufland Case Study
}

\author{
Mădălina Moraru \\ University of Bucharest, Romania
}

\begin{abstract}
Brands' perspectives on consumption and consumers have strongly changed during the pandemic because, lately, they have focused on medical care and innovation. The context of advertising campaigns requires a different approach with specific communication characteristics: safety, medical care, protection, family assistance. The present study focuses on the advertising discourse delivered by retailers on the market to answer consumers' needs. There are two types of perspectives to be considered here: encouraging consumption to survive and looking for solutions and psychological support to get over de-socialisation and fears. Retailers turn from simple suppliers into innovative volunteers who concern themselves with how to diminish fears and insecurity. As a research method, I conducted a multimodal discourse analysis focused on the online advertisements running on Facebook and Instagram to unfold communication strategies, linguistic tools, brand values, and techniques of adaptation to the pandemic. The period considered relevant for this study was during the Romanian lockdown, between March 16 and May 16, 2020, plus another month afterward to observe the consequences of brands' attitudes towards consumers.
\end{abstract}

Keywords: retailers, the pandemic, consumers, communication, advertising JEL classification: L81

Paper type: Research article

Received: Mar 11, 2021

Accepted: Aug 9, 2021

DOI: 10.54820/ZTII7228 


\section{Introduction}

The context of the analysis to what extent retailers have contributed to improving and keeping the balance of daily life during the pandemic refers to many aspects such as social changes, psychological issues, economic consequences, and even financial concerns. According to Naeem (2020), "The outbreak of Covid-19 has brought changes to social, professional and psychological routines, such as financial hardship, self-isolation and stress, loss of jobs and physical and psychological health issues". These perspectives stand for a relevant framework of a real crisis that fundamentally reshaped the entire world, from the common daily life to discovering new coping strategies with unexpecting barriers to survive.

At first sight, the whole context appeared to be a health crisis associated with a virus that turned into a real cavalcade. At this point, everything was experienced at the collective level, both international and national. When statistics conquered news and, generally, media, people started internalising everything very deeply. Humanity learned how to deal with its pandemic, fears, pressure, and insecurity. The moment of leaving isolated to protect their own families or staying away from relatives triggered a different behaviour. However, this was just the beginning of a long-run resistance that progressively yields another society organisation and a form of worldwide solidarity. As Finsterwalder et al. (2020) anticipated in the first pandemic year, "COVID-19 and other pandemics can affect the economy and social life and in particular service providers and service customers". This virus took people's routines by storm and has disturbed the retailers' activity and small businesses.

Significantly, two pillars are extremely important on the market to establish the balance between scarcity and efficient attitude: consumers' behaviour and their consumption, on the one hand, and retailers' strategies, on the other. As expected, consumers' first reaction, regardless of their income, brought to light the excessive purchase of food supply, sanitary products, cookware, and even electronics. This kind of behaviour arose from almost vandalising stores to turn the pantry into a warehouse. Singh et al. (2021) set forth this stockpiling as a usual behaviour during clime disasters, when people look for an immediate solution to feeling safe: "Most supermarket shelves were left empty by residents hoarding goods, a behaviour that is typically observed at the outset of natural disasters such as cyclones or cold weather". Such circumstances were noticed worldwide and emerged on many markets where retailers faced this blind reaction motivated by fears and concerns for survival. At that time, supermarkets realised that they must react immediately by developing strategies to regain consumers' trust and recreate their images as brands, not mere suppliers. As Laato et al. (2020) stated, supermarkets prepared a counteractive response always on the run considering the evolution of the entire pandemic context.

Marketing objectives have not been affected as long as local consumers regain trust and perceive Kaufland, Lidl, Mega Image, Cora, Carrefour as partners, not businesses. All this time, retailers have appealed to the audience by weaving commercial messages with CSR tactics to motivate people to get over the entire pressure. The main hypothesis of this research paper points out the role of strategical advertising communication in the case of retailers' brands as a real fighter against COVID-19 along with the medical system, the military forces, and even the government. Well-developed countries and less-developed nations similarly reacted, and multi-national supermarket chains reconfigured their role in society in the relationship to the consumer.

Reasons for food hoarding emerge from rational and irrational dimensions of humanity as long as consumers convey a range of reactions that trigger emotional 
or unexpected strategies to survive. The present study aims to analyse how Romanian supermarkets have progressively come up with innovative approaches to recover consumers 'trust by changing communication style. This research investigates the retailers' discourse during all stages of the pandemic evolution between March 2020 and June 2020. The purpose of this scientific approach consists in following the supermarkets' role from a simple provider of food and essential products to relevant psychological support.

\section{Background}

\section{Stages of the pandemic during 2020 and 2021}

In Nielsen's study (2020), the consumers' behaviour is analysed across six levels of Coronavirus perception, which might be considered stages of crossing the pandemic period. Briefly, these stages are the following: proactive health-minded buying, virus prevention by investing in hygiene and sanitary means, stockpiling of food products, quarantine living preparation by developing online shopping, restricted living, and discovering new hybrid normality, after restrictions lifting. The first and the last stages have represented pre- and post-pandemic steps, at least until now.

In terms of changing perception towards offline vs. online purchasing, this process reflects the adaptation to the COVID-19 crisis and the embracing digital era phenomenon. Therefore, we can speak about the offline-direct buying experience, which might be associated with pre-pandemic reality and, later on, with relevant restrictions. Even if technology led to significant progress in qualitative services and customer relationships, buyers are still striving for direct contact with products for two reasons: to check their authenticity and enjoy the shopping experience. Besides, visiting a supermarket activates curiosities, new desires, and even pleasure anywhere in the world, although many people do not buy what they appreciate or see. At this level, the attitude of both buyers and consumers is similar no matter the country they live in: "Visiting a store is generally one of the most common activities everyone in the world does." (Dvorak et al., 2021). During the pandemic, technology was not a choice anymore, but the only solution was to stay safe and keep an internal balance. This second stage of the pandemic, respecting the criterion of online delivery food, adapting businesses to vulnerable people, was to reorganise retailers and analyse their priorities: consumers, profit, CSR involvement, style of communication, technology investment. At the beginning of this stage, during the lockdown, vulnerable people, usually the elderly, benefited from home delivery not due to supermarkets applications or online support but being helped by volunteers. Later on, supermarkets came up with innovative solutions to meet the needs of the vulnerable. In this respect, young consumers were used to buying different products online, but less grocery, therefore their next step was easier. For the elderly, this step was done by supermarkets, which urge on developing this audience's digital skills.

Another approach meant to underline the evolution of the pandemic view refers to the relationship between global and local measures taken in this period. In the pre-pandemic stage, which was at the end of 2019 and the beginning of 2020, Covid-19 was a concern at the national level, a disease triggering a health hazard in China.

Shortly after, this crisis turned into a global one, as long as solutions adopted by nations were similar, thus proving their solidarity. During this stage, people experienced real trauma by switching to remote work, living in lockdown for a while, respecting government restrictions, and sadly witnessing the death of some of their beloved ones. This time, even if worldwide measures were similar, the crisis discourse 
was different, relying on the local mentality. Certainly, the very aspect of crisis discourse stands for a research topic in many cases, as it follows: "The global dimensions of a public health crisis, its rapid expansion, and the instant circulation of images depicting deep human tragedy has already initiated a trauma drama process. The public discourse about the coronavirus and its effects is multifaceted, antagonistic, and replete with emotionality; it revolves around the meaning of normality, discipline, and self-discipline, trust, confidence, and distrust toward institutions and political authority." (Demertzis et al., 2020). This phase has been best developed and replicated according to the virus evolution and the country's specificity. The post-pandemic stage started in December 2020 when the longawaited Covid vaccine emerged on the market, which was the global moment when the European Union and nations elaborated strategies to deliver the vaccine simultaneously. This stage has focused on two axes: firstly, it follows collective immunisation. Secondly, it concentrated on vaccination consequences and possible next pandemic waves. In the months to come until the end of 2021, and maybe years, humanity will, for sure, be able to understand this post-pandemic experience better.

\section{Consumers'behaviour before and during the pandemic}

What deserves further consideration for this research is a brief comparison between consumers' behaviour before and during the pandemic. A few factors marked out the main differences: the consumption level, the attitude towards e-commerce, and the loyalty towards brands. Before 2020, humanity strove for fulfilling wishes and dreams by any means, and consumerism was a form of freedom or even an aspiration. Nothing could hinder them from consumption, and brands fought for people's loyalty by looking for strategies adapted to their dreams and selfprojection. Brands focused so much on consumers' personality and beliefs, on campaign insight, and less on CSR. The world was dominated by a global philosophy synthesised utilizing McDonaldization, westernisation, Disneyfication, and Americanisation. The shopping experiences fulfilled consumption dreams and brought about satisfaction. According to Ritzer et al. (2011), consumption at such a large scale implies a spectacular view on reality that removes consumers from dayto-day common life: "Through simulation, cathedrals of consumption can mimic, and render even more spectacular, natural environments, fictional settings, and historical monuments." Mall and shopping centres were metaphorically depicted as "cathedrals of consumption", considering their philosophy, architecture, and, last but not least, the time perception. Consumption was not a necessity but a pleasure.

During the pandemic, consumers became vulnerable people because they risked contamination or even death while being provided with the main supplies, sanitary purchases, or other mandatory acquisitions for common needs. According to Brimmer et al. (2020), the decision factors for vulnerability are the following: medical conditions, social stability, and economic or financial status, helping people cope with their needs through long-term strategies of survival. Locked in their houses, they came back to old habits, focused on cooking, used more online delivery, or learned to get products just utilizing diverse applications. Before the pandemic, customers concentrated on brands 'credibility and their image built utilizing efficient campaigns, while since January 2021, people have given up subjective perceptions of the mandatory products. The gap between delivering promised goods and concerns about Covid infestation during shopping is quite obvious, as Bove stated: "However, whereas in pre-COVID-19, consumers' were concerns about the seller's credibility to deliver upon the promise, now the informational gap is around the 
physical risk of asymptomatic transmission from both front-line staff and other customers who will share the service" (Bove et al., 2020). Last but not least, Anastasiadou et al. (2020) underlined a strong reality that changed consumers' behaviour during the first stages of the pandemic: people completely disregarded Chinese products, as decreasing the level of credibility and quick association with SARS-COV-2.

\section{The brand's involvement in supporting consumers during the pandemic}

Considering that vulnerable people need more help than other social categories for many reasons such as health problems, psychological barriers, and even social support, the pandemic created several opportunities to involve brands and supermarkets in CSR activities.

This time, their efficiency was quite a necessity and a solution to the entire context: "Since the food supply is essential, solutions must be developed to circumvent supermarkets as a potential source of infection for vulnerable populations. In the future, other pandemics or epidemics may reveal different vulnerable population groups." (Breitbarth et al., 2021). The brands whose role was crucial during the lockdown and relaxation measures belong to such categories of products and services: supermarkets, banks, delivery food, communication, Internet providers, media, online platforms. Apart from giants' providers of Internet 'and online resources, almost all these categories were faced with two problems: firstly, employees 'safety during their work and, secondly, the emergence of new consumers 'needs under these circumstances. Consequently, the concept of resilience found its place in this context, being strongly associated with the ability to adapt, respond and come up with innovative solutions to the ongoing crisis, according to well-known scholars (Martinelli et al., 2018).

Supermarkets did not stop their activity because they further moved to online applications, thus connecting people more attractively and safely. Strategies launched supermarkets to overcome consumers' fears during the pandemic was called "signalling theory" by Spence (1974). The word "signal" refers to those stimuli meant to indicate the values and hidden qualities of the respective brand that diminish consumers' uncertainty and specify the extent to which providers communicate most positively. According to Donath (2011), this concept "is to alter the receiver's beliefs or behaviours in ways that benefit the signaler". After the Covid virus was considered one of the most dangerous enemies globally, retailers focused so much on positive messages, on safety headlines of campaigns, encouraging slogans, and urged patience and compliance with government restriction rules. At this moment, retailers were perceived as social actors whose main mission: to represent customers' protection. Carrefour Romania created a buying application entitled Bringo, whose role was to satisfy clients' needs under safe circumstances. Bringo's message recreates the off-store atmosphere online by telling such words: "You buy like you're in the store" (Bringo, 2020). Auchan launched a platform of delivery whose message is very persuasive and turns the store from a simple supermarket into a really helpful, efficient buyer considering this idea of handing over the button: "We do your shopping" (Lolamarket, 2020). Auchan called himself the professional buyer, and Lola Market became a virtual space of successfully online shopping.

At the end of this brief analysis regarding the supermarket's role, while supporting consumers during the pandemic, we reach to Fairlie and Fossen's statement: "Overall, the patterns of sales losses and growth indicate a shift from in-store 
purchases to online purchases, and from restaurants to grocery stores." (Fairlie et al., 2021).

\section{Methodology}

The main purpose of the present study was to unfold the Kaufland communication strategies applied in Romania in the online environment, respectively, on the Instagram account between March 16 and May 16, 2020, plus another month to observe the consequences of the brand's attitudes towards the consumers. Hence, I conducted a multimodal discourse analysis appropriate to investigate Kaufland's communication in such circumstances. According to Van Dijk (1997), one of the most prominent discourse analysis scholars, "the notion of discourse is essentially fuzzy." Language is only the first level of communication, whereas a careful perspective on any message reveals many layers of conveying information. Therefore, analysing how Kaufland communicated on Instagram involves a double approach: firstly, a visual one and, secondly, a linguistic one. In this context, Berger's statement regarding the evolution of this concept enriches the range of theories, which debates discourse analysis: "When discourse analysts started analysing complex texts such as Facebook, they had to deal with words, images, photographs, and videos. The term they use for this kind of analysis is <multimodal> discourse analysis - dealing with different modes of communication" (Berger, 2016).

The main research question refers to how the supermarket adapted its communication to the pandemic content while using social media platforms. Their multimodal discourse was the best qualitative approach to pay enough attention to the brand capital, including advertisements, comments, and posts related to Kaufland products. Therefore, this research followed and adapted Halliday's theory (1985), dividing the discourse analysis into Extralinguistic and Linguistic levels. When it comes to the Extralinguistic level, the main items taken into consideration are the contexts of culture and situation. In this case, the situation is almost the same: the pandemic crisis. The Linguistic level is represented by content levels (semantics and lexicogrammar, which can be translated into the main topics of the slogans or headlines) and the expression levels (phonology, graphology, and gestures).

Table 1

The multimodal discourse of the research

\begin{tabular}{|c|c|}
\hline Extralinguistic level & Linguistic level \\
\hline 1. The Romanian cultural landmarks & $\begin{array}{l}\text { 1. The content levels (the topic of Kaufland } \\
\text { communication) }\end{array}$ \\
\hline \multirow{2}{*}{$\begin{array}{l}\text { 2. The landmarks of diverse situations } \\
\text { during Kaufland's campaigns on Instagram }\end{array}$} & 2. The tone of voice \\
\hline & 3. The lexical field of brand messages \\
\hline
\end{tabular}

Source: Author

This theory can be easily adapted to Kaufland communication on Instagram by framing the multimodal discourse according to the items presented in Table 1.

Consequently, we analysed the Romanian Instagram account belonging to Kaufland based on visual aspects often representing the extralinguistic level of communication, on the one hand, and the linguistic characteristics such as vocabulary, syntax, repetitive words, tone of voice, on the other hand.

\section{Results}

The first dimension of the multimodal discourse analysis under discussion refers to the linguistic level provided by the communication on Instagram. Firstly, between March 
16 and May 15, 2020, and secondly, one month after the national lockdown. The comparison is quite relevant for a better understanding of Kaufland's strategic communication dynamics and adaptation to the pandemic context.

The topic of all Instagram posts (published at least every two days if not daily) focused on several directions such as gratitude, implication, help, safety, celebration, prevention, nutrition, and gastronomy.

When the lockdown started in Romania, the message was very strong and clear, highlighting responsibility and solidarity using such sentences and campaign slogans: "Responsibility makes the difference."

During the Easter holiday, the topic was changed from gratitude and implication to celebration and happiness despite all the restrictions triggered by the lockdown.

As for the tone of voice, the Insta-analysis displayed three categories: the serious and responsible one in most cases, the friendly and joyful one during Easter celebration or spring beginnings, and the relaxed one while advising consumers to adapt their new style of life to the pandemic.

Last but not least, the lexical level fulfilled this linguistic approach of multimodal discourse analysis. The specific outcomes emerge from the hashtags used by Kaufland during the campaigns, on the one hand, and the rich Instagram messages posted at that time, on the other hand. Among the most relevant hashtags revealed by the research, the following seem to be outstanding:

- \#responsibilty

- \#lhelp

- \#together

- \#socheap

- \#Kaufland

- \#whateverwearedoingwelltoday

- \#it'sdoingourselvesgoodtomorrow

- \#pizza

- \#dinner

- \#KClassic

- \#pancakes

- \#dessert

- \#cranberries.

The next Figure synthesises the lexical field analysed relying on frequency criterium. This word cloud frames the CSR activity developed by the retailer during the first pandemic week as the entire nation was overwhelmed by fears and uncertainty.

As expected, the main interest of messages is oriented towards responsibility, employees' efforts, staying safe, and observing protection measures to prevent infections. Easter posts offer not only a breath of fresh air but also a consolation. The message was full of hopes but adapted to the entire context: "Spend the Easter day with traditional food. Call your nearest and dearest and enjoy the time spent together from far away. We stay home, but tomorrow all the Romania will be ours."

The second dimension of our research method refers to the extralinguistic level, which is less generous in terms of information and details. When it comes to Romanian cultural landmarks, or in other words of local identity, the German retailer firstly globally approached the sanitary crisis.

Kaufland wove the local visual symbols with the global ones. For instance, in the first two weeks of lockdown, the red colour as a background of the post reminded us of Red Cross advertisements. 
Figure 1

The Lexical map of Kaufland's Instagram posts during the lockdown

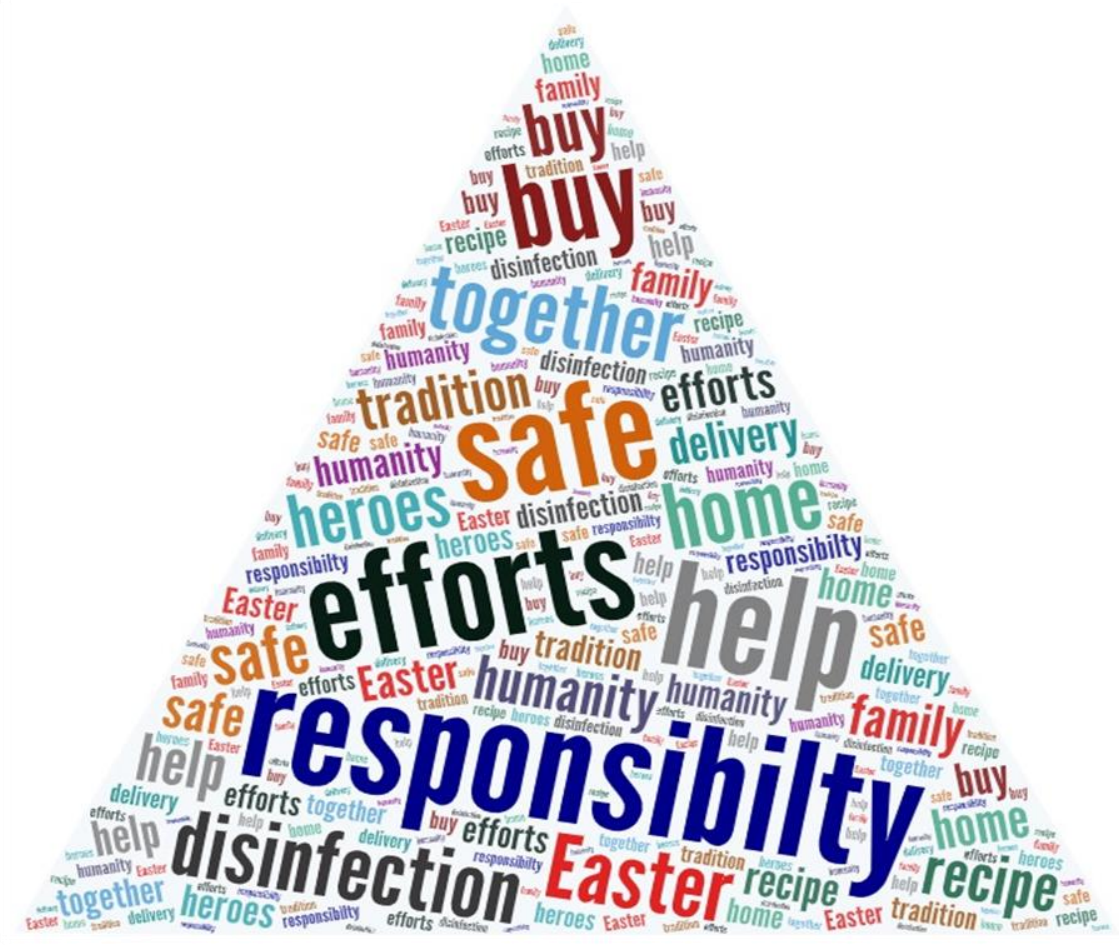

Source: Author's illustration

Ads were simple, explaining the new sanitary prevention advice meant to reorganise people's life.

Around the Easter celebration, the local identity drew consumers' attention by posting visual representations of Romanian traditions: the painted eggs, Easter sweet bread, and the new approach of Easter family lunch. Besides, the partnership with the Royal Foundation, Margaret of Romania stands for another sign of national history.

At the end of lockdown, the retailer prepared the target for normality, inviting them to enjoy other activities such as enjoying a movie by ordering or cooking a pizza from Kaufland.

As for the landmarks that framed or outlined diverse situations of the crisis, Kaufland's Instagram posts unveiled the evolution of the pandemic crisis. Consequently, ads set forth the stockpiling and urged to recover people's trust and stop this excessive buying attitude.

Then, Kaufland emphasised its pioneering stage when it decided to deliver for free and activated volunteers to help seniors. Posts insisted so much on new pandemic rules, communicating a guide of staying healthy and safe. Then, most frequent posts tackled the pandemic lifestyle, looking for solutions to ease the transition from a dynamic life to a static one.

Looking forward to investigating the post-lockdown communication delivered by Kaufland on Instagram, we observed that the retailer daily posted ads and messages, thus enriching the brand's visibility. Between May 16 and 16 June 2020, the extralinguistic and linguistic discourses completely changed the approach. The 
linguistic level seems to be quite representative given that after the lockdown, the entire society strove to recover the time and the guilty pleasures of life. Most Instaposts $(51,61 \%)$ developed topics on recipes and best ingredients. All the other themes refer to family, health, gaming, childhood, and future. The tone of voice covers a range of diverse references, most of them preoccupied with increasing the level of optimism and happiness. What is predominant with $38,70 \%$ is the positive tone of voice followed by a relaxed and friendly attitude with $22,58 \%$. The other $38,71 \%$ is represented by a range of tones of voice such as nostalgic, challenging, smart, persuasive, and playful.

The lexical field emphasised the aspiration to overcome the pandemic context to return to the life consumers have. Thus, the first message posted on May 16 reveals the well-being and need to convey happiness by saying: "Change the world. Enjoy things day-by-day." Following the same analysis pattern, the lexical field relies on two directions: the diversity of hashtags, on the one hand, and the messages, on the other. Even if the Kaufland Instagram hashtags appeal to the Romanian market, they use English to synthesise messages. Each post has at least two or even three hashtags describing the variety of communication. Over 20 hashtags observed food quality (\#delicious, \#mozzarella, \#cheese, \#spinach, \#waffels, \#strawberry, \#goudacheese, \#perfectsandwitch etc.), 10 of them underlined moment of consumption (\#breakfast, \#dinner, \#Sunday, \#breakfastideas, \#morning). In contrast, the rest paid attention to Kaufland services (\#KClassic, \#Socheap, \# So simple).

As for the next issue, regarding the lexical field provided by the rich descriptive messages, Figure 2 offers a broad perspective of communication as follows:

Figure 2

The Lexical map of Kaufland Instagram posts after the lockdown

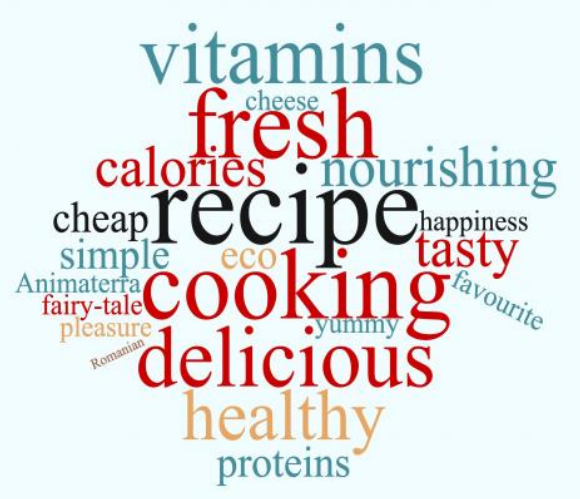

Source: Author' illustration

Certainly, Kaufland answers people's needs for healthy food, delicious recipes, fresh vegetables, and fruits, as if buyers had never experienced the pandemic or the fears of loneliness, isolation, and limited consumption. In other words, all posts in the first month after lockdown were optimistic, inviting to enjoy life and recover trust step by step. 
The second part of multimodal discourse analysis emerges from investigating the Romanian cultural landmarks unveiled by the visual posts and the diverse contexts of Kaufland Instagram communication. In 4 situations, the Romanian issues were absent. The landmarks remind us of international gastronomy in the other four situations, such as German, Italian, Portuguese, and French. Regarding the national references, Kaufland bears the sign of localised campaigns by using Romanian artists names (Smiley), athletes (Cristina Neagu), traditional food (recipes), popular graphic design on plates, traditional Romanian dishes (chopping boards, the wooden pestle, and mortar, wooden spoons, rolling pins, and clay pie dishes) and ingredients (berries, coriander, garlic, parsley, and dill). The situations when Kaufland become part of people's lives are related to consumption moments or significant period such as morning, breakfast, Sunday, lunch, dinner, celebration, or, why not, movie time.

\section{Discussion}

Kaufland reacted very quickly, learning how to cope with this challenge from one day to another. So, the retailer understood its social role from the first moment of lockdown, supporting consumers and providing them with supplies and trust. The retailer came up with solutions to adapt on the go and became a real partner, giving the supportive message, partnership with Glovo, and the volunteering program. Certainly, Kaufland's attitude triggered a chain reaction on the market and hindered consumers from experiencing panic. The Kaufland discourse was not a homogeneous one because it did not establish a balance between the extralinguistic and linguistic levels. The latter one strove to encourage people, provide information, come up with strong solutions, and appeal to people's sense of humanity. However, the topic, the tone of voice, and even the pandemic situations developed by the retailer Instagram campaigns accounted for a very active behaviour and turned the advertising message into a CSR one.

In the second part of the present research, the retailer recovered its image before the lockdown, inspiring stability, creativity, and balance every day. Therefore, this step corresponds to the well-promised direction based on the hashtag \#it'sdoingourselvesgoodtomorrow transmitted during March 15 and May 15, 2020. The positive tone of voice, the idea of changing the world's perception, and even the lexical field reflect the desire to accelerate the process of returning to prepandemic life, when cooking, recipes, fresh vegetables, and delicious food stand for serious subjects to be discussed.

Comparing the first and the second stage of the multimodal discourse analysis, the message is quite homogeneous at the Linguistic level, in terms of lexical field, topic, and tone of voice, since the entire strategy is based on escapism, on releasing from fear of the virus. As for the balance between the Extralinguistic and Linguistic aspects analysed between May 16 and June 16,2020, one can notice an obvious correspondence because the positive tone and the topics are specific to the Romanian contexts and traditions in most cases.

\section{Conclusion}

Kaufland communication adapted to the pandemic on the go throughout the lockdown following a few significant aspects of Linguistic level, all of them connected to people 's interests: safety, health, responsibility, volunteering, common efforts to get over the entire situation. Employees and buyers were seen as a single target defined by a simple word: humanity. Later on, in the second half of May and 
at the beginning of June, communication explicitly displayed the need to recover the psychological normality. Consumers are invited to re-discover their pleasures, respectively cooking, eating, and travelling through gastronomy and exotic recipes. Therefore, this approach was the first sign of recovering their freedom because the government had partially given up restrictions. Therefore, at the Extralinguistic level, the approach was almost opposite in those two stages of the analysis, which was quite understandable. Kaufland communicated according to consumers' needs, on the one hand, and met the Government safety measures. At this level, Kaufland appeared as a mediator between consumers' fears and needs, on the one hand, and the temporary pandemic restrictions, on the other.

Therefore, Kaufland communication followed a well-structured strategy in the second stage of this research. In contrast, everything was progressively established during the lockdown in the first part, considering that all messages were another voice of protecting people. That way, the brand accomplished not just the marketing objectives but also the social one, which was, actually, the most relevant at that moment because consumers were experiencing unprecedented fears and panic.

As for the limits of this research, it is obvious that an extended investigation of the entire Kaufland communication between 2020 and 2021 would reveal a betterstructured strategy and another level of multimodal discourse analysis, as well. In this study, we follow the first moments of the pandemic context to catch the retailer's adaptation to the whole crisis. A further study would be quite relevant as long as it compares with another similar retailer from Romania or even abroad.

In conclusion, Kaufland reacted promptly between March and June 2020 and grasped the marketing impact and the social, psychological, and even the health contexts, thus bringing their contribution to help get over this unexpected worldwide situation on the Romanian market.

\section{References}

1. Anastasiadou, E., Chrissos, M., Karantza, I., Vlachakis, S. (2020), "The coronavirus' effects on consumers behavior and supermarket activities: insights from Greece and Sweden", International Journal of Sociology and Social Policy, Vol. 40 No. 9/10, pp. 893-907.

2. Berger, A. A. (2016), "A Discourse on Discourse Studies", Symposium: Worlds of representations, Vol. 53, pp. 597-602.

3. Bove, L. L., Benoit, S. (2020), "Restrict, clean and protect: signaling consumer safety during the pandemic and beyond", Journal of Service Management, Vol. 31 No. 6, pp. $1185-$ 1202.

4. Breitbarth, E., Groß, W., Zienau, A. (2021), "Protecing vurnerable people during pandemics through home delivery of essential supplies: a distribution logistics model", Journal of Humanitarian Logistics and Supply Chain Management, Vol. 11 No. 2, pp. 227247.

5. Brimmer, A., Chin, V., Gjaja, M., Haslehner, R. (2020), "Protect the vulnerable - protect us all", available at: https://www.bcg.com/publications/2020/protecting-vulnerablepopulationsprotects-all-populations.aspx (25 June 2020).

6. Bringo (2020), "Bringo", available at: https://www.bringo.ro/ro/ (11 June 2021)

7. Demertzis, N., Eyerman, R. (2020), "Covid-19 as cultural trauma", American Journal of Cultural Sociology, Vol. 8, pp. 428-450.

8. Donath, J. S. (2011), "Signals, Cues and Meaning", available at: https://smg.media.mit.edu/papers/Donath/SignalsTruthDesign/SignalsCuesAndMeaning. pdf (11 June 2021)

9. Dvorak, J., Komarkova, L., Stehlik, L. (2021), "The effect of the COVID-19 crisis on the perception of digitisation in the purchasing process: customers and retailers' 
perspective", Journal of Entrepreneurship in Emerging Economies, Vol. 13 No. 4, pp. 628647.

10. Fairlie, R., Fossen, F. M. (2021), "The early impacts of the COVID-19 pandemic on business sales", available at: https://doi.org/10.1007/s $11187-021-00479-4$ (5 May 2021)

11. Finsterwalder, J., Kuppelwieser, V. (2020), "Equilibrating resources and challenges during crises: a framework for service eco-system well-being", Journal of Service Management, Vol. 31 No 6, pp. 1107-1129.

12. Halliday, M. A. K. (1985), An introduction to functional grammar, Arnold, London.

13. Laato, S., Islam, A. K. M. N., Farooq, A., Dhir, A. (2020), "Unusual purchasing behavior during the early stages of the COVID-19 pandemic: the stimulus-organism-response approach", Journal of Retailing and Consumer Services, Vol. 57, pp. 1-12.

14. Lolamarket (2020), "Lolamarket", available at: https://lolamarket.com/ro/ro/?fl=true (11 June 2021)

15. Martinelli, E., Tagliazucchi, G., Marchi, G. (2018), "The resilient retail entrepreneur: dynamic capabilities for facing natural disasters", International Journal of Entrepreneurial Behavior \& Research, Vol. 24 No. 7, pp. 1222-1243.

16. Naeem, M. (2020), "The role of social media to generate social proof as engaged society for stockpiling behaviour of customers during Covid-19 pandemic", Qualitative Market Research, Vol. 24 No. 2, pp. 1-21.

17. Nielsen (2020), "Key consumer behavior thresholds identified as the coronavirus outbreak", available at: https://www.nielsen.com/us/en/insights/article/2020/keyconsumer-behavior-thresholdsidentified-as-the-coronavirus-outbreak-evolves/ (20 June 2020).

18. Ritzer, G., Stepnisky, J. (2011), "Means of consumption/cathedrals of consumption", in Beckert, J., Zafirovski, M. (Eds.), International Encyclopaedia of Economic Sociology, London, Routledge, pp. 440-442.

19. Singh, G., Aiyub, A. S., Greig, T., Naidu, S., Sewak, A., Sharma, S. (2021), "Exploring panic buying behavior during the COVID-19 pandemic: a developing country perspective", available at: https://doi.org/10.1 108/IJOEM-03-2021-0308 (11 June 2021)

20. Spence, M. (1974), "Competitive and optimal responses to signals: an analysis of efficiency and distribution", Journal of Economic Theory, Vol. 7 No. 3, pp. 296-332.

21. Van Dijk, T. (Ed.) (1997), Discourse as Structure and Process. Discourse Studies: A Multidisciplinary Introduction, Sage, Thousand Oaks.

\section{About the author}

Mădălina Moraru is an Associate Professor Ph.D. and researcher at the University of Bucharest, Romania. Her main interests are the anthropological and narrative approaches to advertising. As a member of the Edcom-EACA, ECREA, and ESA, she is active and in touch with cutting-edge research worldwide. Mrs. Moraru is a board member of the Edcom, re-elected in the Research Committee. From 2010 to 2013, she received postdoctoral fellowships from The University of Oklahoma, US, and Staffordshire University and Buckinghamshire New University, UK, conducting a strategic European grant on glocalisation. She authored many chapters, over 24 research articles, as well as two books: "Myth and Advertising" (Bucharest, 2009) and "Advertising Stories. From Inspiration to Strategy" (Bucharest, 2015). She gets involved in the Romanian industry's projects as a constant member of the Effie Juries. In 2016, she was among the Romanian project AcademIAA, developed by the IAA Romania to bridge academia and professionals. The author can be contacted at madalina.moraru@fjsc.ro 